\title{
Adherence of heart failure patients to exercise: barriers and possible solutions A position statement of the Study Group on Exercise Training in Heart Failure of the Heart Failure Association of the European Society of Cardiology
}

Viviane M Conraads, Christi Deaton, Ewa Piotrowicz, Nuria Santaularia, Stephanie Tierney,
Massimo F Piepoli, Burkert Pieske, Jean-Paul Schmid, Kenneth Dickstein, Piotr P Ponikowski and Tiny Jaarsma

\section{Linköping University Post Print}

N.B.: When citing this work, cite the original article.

This is a pre-copy-editing, author-produced PDF of an article accepted for publication in European Journal of Heart Failure following peer review. The definitive publisherauthenticated version

Viviane M Conraads, Christi Deaton, Ewa Piotrowicz, Nuria Santaularia, Stephanie Tierney, Massimo F Piepoli, Burkert Pieske, Jean-Paul Schmid, Kenneth Dickstein, Piotr P Ponikowski and Tiny Jaarsma, Adherence of heart failure patients to exercise: barriers and possible solutions A position statement of the Study Group on Exercise Training in Heart Failure of the Heart Failure Association of the European Society of Cardiology, 2012, European Journal of Heart Failure, (14), 5, 451-458.

is available online at: http://dx.doi.org/10.1093/eurjhf/hfs048

Copyright: Oxford University Press (OUP): Policy B http://www.oxfordjournals.org/

Postprint available at: Linköping University Electronic Press http://urn.kb.se/resolve?urn=urn:nbn:se:liu:diva-77728 


\section{Adherence to exercise of heart failure patients: barriers and possible solutions. A position statement of the Study Group on Exercise Training in Heart Failure of the Heart Failure Association of the European Society of Cardiogy}

\section{Authors: Viviane M Conraads ${ }^{1}$, Christi Deaton ${ }^{2}$, Ewa Piotrowicz ${ }^{3}$, Nuria Santaularia ${ }^{4}$, Stephanie Tierney ${ }^{5}$, Massimo F Piepoli ${ }^{6}$, Burkert Pieske ${ }^{7}$, Jean-Paul Schmid ${ }^{8}$, Kenneth Dickstein $^{9}$, Piotr P Ponikowski ${ }^{10}$, Tiny Jaarsma ${ }^{11}$.}

${ }^{1}$ Department of Cardiology, Antwerp University Hospital, Wilrijkstraat 10, 2650 Edegem, Belgium; University of Antwerp; University of Antwerp, Universiteitsplein 1, B-2610 Antwerp, Belgium.

${ }^{2}$ School of Nursing, Midwifery \& Social Work, the University of Manchester, and Central Manchester NHS Foundation Trust, Manchester, United Kingdom.

${ }^{3}$ Department of Cardiac Rehabilitation and Noninvasive Electrocardiology, Institute of Cardiology, Warsaw, Poland.

${ }^{4}$ Department of Rehabilitation, Althaia, Xarxa Assistencial de Manresa, Manresa, Barcelona, Spain.

${ }^{5}$ School of Nursing, Midwifery \& Social Work, the University of Manchester, Manchester, United Kingdom.

${ }^{6}$ Heart Failure Unit, Cardiac Dept., G. da Saliceto Hospital, AUSL Piacenza, Piacenza, Italy.

${ }^{7}$ Department of Cardiology, Medical University Graz, Austria.

${ }^{8}$ Department of Cardiology, Cardiovascular Prevention \& Rehabilitation, Bern University Hospital, and University of Bern, Switzerland.

${ }^{9}$ University of Bergen, Bergen, Norway; Stavanger University Hospital, Stavanger, Norway.

${ }^{10}$ Department of Heart Diseases, Medical Academy, Military Hospital, Wroclaw, Poland.

${ }^{11}$ Department of Social and Welfare Studies, Faculty of Health Sciences, Linköping University, Norrköping, Sweden. 


\section{Correspondence:}

Viviane M Conraads, MD, PhD

Department of Cardiology

Antwerp University Hospital

Wilrijkstraat 10

2650 Edegem, Belgium

Tel: +32 38214672 - Fax: +32 38213973

E-mail: Viviane.Conraads@ua.ac.be 


\section{Abstract:}

The practical management of heart failure remains a challenge. Not only are heart failure patients expected to adhere to a complicated pharmacological regimen, they are also asked to follow salt and fluid restriction, and to cope with various procedures and devices. Furthermore, physical training, whose benefits have been demonstrated, is highly recommended by the recent guidelines issued by the European Society of Cardiology, but it is still severely underutilized in this particular patient population. This position paper addresses the problem of non-adherence, currently recognized as a main obstacle to a wide implementation of physical training. Since the management of $\mathrm{CHF}$, and even more, of training programs, is a multidisciplinary effort, the current manuscript intends to reach cardiologists, nurses, physiotherapists as well as psychologists working in the field.

Keywords: Adherence, exercise training, barriers, heart failure. 


\section{Introduction}

It has taken exercise training 20 years to evolve from an experimental setting to a Class I recommended non-pharmacological treatment for all stable heart failure (HF) patients (1). Patients clearly benefit from regular physical activity by tackling the hallmarks of the syndrome, such as early fatigue and dyspnea with exertion. The positive effects in patients with HF and reduced ejection fraction (HFREF) have been well established since the nineties (2). Evidence has recently emerged, that HF patients with preserved ejection fraction (HFPEF) equally improve their physical capacity following exercise training $(3,4)$.

There is robust evidence that CHF patients who engage in exercise training increase their peak aerobic and submaximal exercise capacity (5), mainly by reversing peripheral abnormalities, such as endothelial dysfunction, skeletal muscle wasting and ventilatory inefficiency (6)(7). Despite initial concerns, aerobic exercise training also favourably affects left ventricular remodelling (7). Nevertheless, implementation in clinical practice is still very poor (8).

The delivery of compelling data on the effects on mortality, morbidity, safety and quality of life, as well as on the feasibility is instrumental to facilitate the transition from selective implementation to a more general adoption of exercise training.

Because most of the published randomised studies reflect small single centre experience, until recently, confirmation on the benefits of exercise training in $\mathrm{CHF}$ had to be derived from meta-analyses $(5,9)$. Clearly, the results of the "Heart Failure: A Controlled Trial Investigating Outcomes of Exercise Training" (HF-ACTION) trial were eagerly awaited, in which $2331 \mathrm{HF}$ patients were randomized either to an aerobic exercise training or a usual care group in order to determine whether the intervention is able to reduce all-cause mortality or all cause hospitalization and to improve quality of life (10). Disappointing at first sight, after a median follow-up of 30 months, exercise training led only to a non-significant $7 \%$ reduction in all-cause mortality or hospitalization. However, after adjustment for pre-specified major prognostic factors, the composite primary end point was significantly reduced by $11 \%$ (adjusted HR 0.89 [95\% Cl, 0.81-0.99], $\mathrm{P}=0.03$ ). 


\section{Non-adherence: the Achilles' heel of exercise training programs}

Several arguments have been put forward to understand why the results of HF-ACTION failed to meet the expectations (10). These arguments include the non-uniform adherence to evidence-based medical and electrical therapy, a high percentage of exercise cross-over from patients allocated to the usual care arm and possibly, a low training stimulus. Moreover, the HF population studied in HF-ACTION showed a low risk profile (mean age 59 years, and less than $30 \%$ female, with preserved exercise tolerance). This is in contrast with the classical characteristics of patients after recent hospital admission, such as those followedup in the $\mathrm{COACH}$ trial (11), with a mean age of 71 years, 38\% women, with important comorbidities such as COPD (27\%), prior stroke (10\%) and atrial fibrillation. According to previous experience, the most severe subgroups are most likely to benefit from a supervised exercise training program in term of morbidity and mortality (9).

The most likely explanation, however, reveals the Achilles' heel of exercise training, namely: non-adherence. Only approximately $40 \%$ of patients in the exercise group reported weekly training volumes at or above the recommended 90 minutes per week at month 3 , or 120 minutes from month 3 to month 12 (12). This low level of adherence to the prescribed training regimen is reflected in the considerably smaller than expected increments achieved in terms of peak oxygen uptake (peakVO $\mathrm{V}_{2}$ (median of $0.6 \mathrm{ml} / \mathrm{kg}^{-1} / \mathrm{min}$ ) and 6 minutes walking distance (6MWD) (median of 20 meters) after 3 months. Although differences may relate to exercise intensity and duration, the observed weighted mean difference in peak $\mathrm{VO}_{2}$ and $6 M W D$, based on the data from 1126 patients randomized in 29 trials, was $2.16 \mathrm{ml} / \mathrm{kg} / \mathrm{min}$ and 40.9 meters, respectively (5). Second, post-hoc analyses suggest that adherence to larger exercise volumes in HF-ACTION, resulted in significantly greater benefit with regard to peakVO $\mathrm{V}_{2}(12)$. Every metabolic-equivalent (MET)-hour/week increment in achieved exercise intensity produced a $5 \%$ reduction in the 90 -day risks of both death/hospitalization and CV death/CV hospitalization ( $p=0.003$ and $p=0.009$, respectively) (13).

The results of HF-ACTION exemplify the inherent limitations of current strategies used to introduce lifestyle changes. Despite the supportive environment of a well-conducted randomized controlled trial, including formal education, activity logs, telephone contact, regular visits to the clinic and heart rate monitoring, the median attendance of supervised training sessions was only 1.8 times per week, as compared to 3 times per protocol.

Also in the $\mathrm{COACH}$ study, only $39 \%$ of patients reported to be compliant with exercise recommendations, despite the fact that $80 \%$ of them recognized its importance (14). Figures on non-adherance may depend on the evaluation method (i.e., questionnaires, activity logs, heart rate monitors, pedometers, telemonitoring) and the measures put into place to optimize adherence, such as supervised versus home-based interventions. McKelvie et al. (15) reported a significant decline from $2.3 \pm 0.4$ attended sessions per week during the first 
supervised 3 months to $1.7 \pm 0.4$ sessions after 12 months home-based training.

In spite of being the most vulnerable and physically deprived, HF patients are not exceptionally unwilling or resistant to implement physical activity into daily life. Based on interviews obtained in $>24000$ healthy subjects and patients post-myocardial infarction recruited for the INTERHEART study (16), the overall percentage of sedentary behaviour during leisure time ranged between 37 to $69 \%$ in both high and low-income countries. Although exercise-based rehabilitation (17) for patients after revascularisation or myocardial infarction is associated with a significant mortality reduction of $20-30 \%$, the adherence to cardiac rehabilitation is low with a percentage of drop-out ranging from $33-56 \%$ during the actual program (18).

The Study Group on Exercise Training in HF of the Heart Failure Association recently published a consensus document that provides practical information on the organisation and application of exercise training in CHF patients (19). The current paper addresses the problem of non-adherence, currently recognized as a main obstacle to a wide implementation of physical training. Since the management of $\mathrm{CHF}$, and even more, of training programs, is a multidisciplinary effort, $(20,21)$ the current manuscript intends to reach cardiologists, nurses, physiotherapists as well as psychologists working in the field.

\section{How to define adherence to exercise.}

Adherence is defined by the World Health Organisation (WHO) as the extent to which a person's behaviour - taking medication, following a diet, and/or executing lifestyle changes corresponds to the recommendations of a health care provider (22). Exercise adherence is the extent to which a patient acts in accordance with the advised interval, exercise dose and exercise dosing regimen. The unit of measure for adherence is performed exercise doses per defined period of time reported as a proportion of prescribed exercise doses undergone at the prescribed time interval.

Exercise persistence is the accumulation of time from initiation to discontinuation of therapy, measured by time metric (e.g. number of weeks/months etc. to discontinuation).

Practically speaking, patients can be divided into three categories in terms of their adherence to prescribed therapeutic regimen, such as exercise (this classification was originally introduced to evaluate the adherence to hypertensive drug administration (22-24)). The first category is adherent patients, i.e. patients who adhere both to the number of training sessions prescribed as well as to the duration of the prescribed cycle (e.g. the duration of a structured program) in at least $80 \%$. The second category consists of non-adherent patients, who adhere less than $20 \%$ to the prescribed number of trainings and their duration. The third category corresponds to the partially adherent patients who carry out the prescribed exercises, yet tend to omit some of them or do not carry them out at the prescribed duration. 


\section{How to assess adherence to exercise.}

Exercise training is ideally prescribed according to the FITT acronym, which stands for frequency, intensity, time and type. Frequency refers to the number of physical training sessions during a specific time period; intensity refers to the physiological effort associated with participation in a special type of exercise training; time refers to the duration of execution of a single exercise training session; type finally indicates the exercise modality. Three different modalities are generally prescribed in HF patients, ie aerobic endurance (continuous and interval), strength/ resistance training and respiratory muscle (19). Therefore, assessment of adherence should include all the above mentioned components (table 1).

The assessment of patients' adherence differs depending on whether the exercise training program is hospital- (in- or out-patient setting) or home-based.

Adherence can be assessed by subjective and/or objective methods. The subjective methods include physical activity questionnaires and diaries filled in by patients. Objective methods include the recording of data from pedometers, accelerometers, pulsometers (heart rate monitoring) and ECG telemonitoring (25). The advantages and disadvantages of these different methods are presented in Table 2 . In order to definitely rule out whether exercise training has a benefit on morbidity and mortality, adherence to prescribed exercise regimens, as well as physical activity performed in addition to the prescribed regimen (whether it concerns a training or a control group, where some form of physical activity is always advised as part of good medical practice in the follow up of a cardiac patient) should be taken into account. Nevertheless, it is likely that adherence to exercise in daily practice is even more problematic compared to pharmacological therapy, where it is known to be quite poor, especially in a home-based, non-monitored setting. In the hospital-based setting, adherence can be directly monitored by the caring staff. Instead in a home-based setting, different options have been envisaged: regular home visits by nurses, planned controls in a rehabilitation or specialised centre, remote monitoring performed via telephone, web, or by transmission of a report to a monitoring centre, can be considered.

\section{Barriers for exercise in HF}

According to the WHO, adherence is simultaneously influenced by several factors, such as 'patient related factors' ,'social and economic factors', 'factors related to the health care team/system', 'condition related factors' and 'therapy related factors'. Knowledge regarding patients' barriers for non-adherence and reasons for dropout from cardiac rehabilitation programs may provide guidance to design successful strategies to increase participation. The main factors are discussed below (Table 3). The ability of patients to follow exercise recommendations is frequently compromised by more than one barrier, usually related to 
different aspects of the problem.

\section{Patient-related factors}

Older age, a low level of education, being socioeconomically disadvantaged and minority status are related to poor adherence to cardiac rehabilitation in general. $(26,27)$. In addition, there are specific reasons, reported by cardiac patients themselves, which reduce adherence to physical activity, such as having inadequate social support, anxiety and depression $(26,28$ 32). Other factors include logistical problems, such as travelling to the rehabilitation centre, lack of motivation for exercise, not having time or laziness (33-38). Barriers may be different for men and women (38). Specifically women described exercise as tiring and painful and they dislike public or mixed-gender exercise programs (26). Women are more likely to drop out because of medical (non-cardiac) problems and family obligations, and may have less time to devote to exercise than men because of their multiple roles and commitments to work, family and community activities. In contrast, male cardiac patients more often reported factors, such as being 'too lazy', finding that the exercises were 'boring' and that cardiac rehabilitation programs 'interfered with work' $(37,39)$. Specifically for HF patients, we know that their mean age is over 70 years, patients are often living alone, and find themselves less supported to be active or to bring them to a training facility $(40,41)$. Some HF patients also consider that slowing down and becoming more sedentary is part of the normal ageing process (42).

\section{Social and economic factors.}

Social factors can both positively and negatively affect the possibilities to exercise. For example marital disruption negatively impacts access to resources and support necessary for positive lifestyle changes in cardiac patients (26). Economic factors such as a lack of reimbursement for participation in a rehabilitation program or transportation issues can be barriers for patients with lower socio-economic status.

\section{Health care team/system,}

One of the health care system factors that is a barrier for adherence to exercise is related to the limited availability of rehabilitation programs or exercise facilities that are suitable for HF patients. Not all cardiac rehabilitation centres have special programs for HF patients and patients might not be able to participate fully in existing cardiac rehabilitation programs due to their symptoms, physical status or length of a program. Another factor is the capacity and expertise of cardiac rehabilitation centres, to serve a large HF population. A barrier related to the heart care team is the lack of referral of HF patients to cardiac rehabilitation but also even mentioning the importance of physical activity. In general less then $60 \%$ of cardiac patients 
eligible for cardiac rehabilitation actually are referred by their physician (43) even much lower depending on country. In a recent national audit of cardiac rehabilitation in the UK, only $1 \%$ of patients were referred for HF, and a quarter of programs excluded patients with HF (44). Another study showed that many providers never mentioned exercise, leading patients to believe it less important, or gave advice that was vague or even discouraging (42).

\section{Condition related factors}

Factors related to the condition of the patient are the severity of symptoms, the level of disability, the rate of progression, and the impact of co-morbidities, leading to a more complex regimen with a higher risk for non-adherence (40). HF symptoms such as fatigue and symptoms are clear barriers to start and continue exercising. Exacerbation leading to hospitalization often leads to deconditioning and might demotivate patients to resume their activities. Comorbidity is a serious problem in HF patients (45) that might hinder patients' ability to follow a standard exercise recommendation or program, and both duration of HF and increasing number of comorbid conditions are predictors of non-adherence (41). Special attention should be paid to patients with depressive symptoms or cognitive problems that often coexist in $\operatorname{HF}(46,47)$.

Patients reported that fluctuating health and co-morbid conditions affected their engagement in exercise, although patients differed as to willingness to persist in activity despite symptoms. Conditions such as arthritis were more of a barrier to exercise than HF for some patients, and cardiovascular clinicians seemed unable to offer much support in this area (42). Patients also may not consider that exercise is specifically beneficial for HF, as well as overall health (42).

\section{Therapy related factors.}

Although at first sight exercise might not be a complicated advice, for a significant proportion of cardiac patients it is difficult to include regular exercise into their daily life. Some patients would prefer activities that are useful, such as gardening, or that incorporate a social element, such as bowling or dancing rather than a pure exercise regimen (42). Patients allowed to choose their own exercise activities following a period of supervised exercise training, increased submaximal exercise capacity over the next 12 months compared to those involved in continuously supervised exercise or usual care (48).

\section{Motivation}

Motivational factors are those which cause someone to behave or act in either a goalseeking or satisfying manner (49). There is only limited literature describing factors that increase the motivation for physical activity. These are mainly related to the factors 
associated with the patients themselves, the social interaction during exercise, the condition of the patient and the therapy. In a small qualitative study of $22 \mathrm{HF}$ patients (7 women) in NYHA functional class I - III, patients who were self-motivated to be more active were better able to describe tangible benefits of exercise such as maintaining autonomy, or reducing dizziness. Interestingly, they seldom mentioned benefits specifically related to their HF (42).

Cardiac patients in general report different motivational aspects related to following the advice to exercise such as increasing self-confidence $(38,50,51)$, to "sorting your life out" (36), to improve performances of tasks at home simply, enjoyment of exercise $(37,50,52)$ or to improve appearance. The factors might be motivating to HF patients, since regular exercise might increase their abilities to do more daily activities and tasks at home, leading to a more highly valued independence $(6,53)$.

Another motivating factor might be a higher social interaction either with family members or with others $(36,38,50)$. Although HF patients not always have a strong social support system (54), they might be motivated to be active in an exercise group or with family members to be less isolated.

In general, motivational factors reported by men and women differed. Men's motivational factors were often related to getting physically fit (health, weight loss) (50)and professional support $(50,55)$, whereas women reported factors related to social interaction, social support $(27,52,56)$ and prevention of osteoporosis $(37)$.

\section{Overcoming Barriers: What Strategies Work?}

Despite the known problem of poor adherence to exercise in patients with $\mathrm{HF}$, there is unfortunately little evidence for interventions to improve adherence. In a systematic review of controlled studies evaluating interventions to increase initiation and maintenance of exercise, 9 studies in 11 papers were reviewed (57). Only 4 studies included more than 100 patients, and 5 followed patients for 6 months or more. Exercise was measured in multiple ways, primarily self-reported (either through recall or by concurrent diary) frequency of attendance at supervised exercise sessions, frequency of reported exercise, calculated energy expenditure in $\mathrm{kcal} / \mathrm{kg} / \mathrm{day}$, and minutes spent walking or in exercise sessions. Only one

study used an objective measure of distance walked (pedometer), and none of the published papers reported MET hours.

In the short term ( $\leq 6$ months), cognitive behavioural strategies such as those used in motivational interviewing, and strategies that enhanced patient self-efficacy for exercise, have been successful in increasing exercise in intervention groups by $25-30 \%$ compared to controls. These strategies included goal setting, exercise prescriptions, problem-solving, feedback, positive reinforcement and group interaction, and were primarily part of studies with a clear theoretical framework. Education alone was not effective. No studies showed a 
significant long-term effect, and adherence declined between 6 and 12 months (57). From this, it would seem logical that a second dose of the intervention to increase adherence is needed around 6 months.

Studies are increasingly targeting self-efficacy in undertaking exercise, as it has been shown to predict physical activity in HF and other long-term conditions, and to have positive short-term effects on adherence to exercise in HF (58-62). Self-efficacy can be developed through supervised exercise training, peer support and seeing peers undertake exercise, realistic goal setting, and support from family and friends $(57,63,64)$.

Table 4 presents recommendations for clinicians to help patients overcome barriers to exercise.

\section{Conclusion}

Exercise is a crucial component of therapy for patients with HF, but unfortunately still poorly implemented, and even those patients who are enrolled in a supervised exercise training or multidisciplinary cardiac rehabilitation program show low adherence. Multiple are the barriers and multi-factorial the reasons for non-adherence to physical activity and exercise. Our interventions should aim to address all these causes, and all professionals should ask about and encourage physical activity when seeing patients to emphasise its importance.

Even when the amount of time spent exercising as part of a programme is small, supervised and encouraged exercise is likely to lead to a more active lifestyle, so that the effective "dose" of exercise may be considerably greater than that directly prescribed.

\section{References:}

(1) Dickstein K, Cohen-Solal A, Filippatos G, McMurray J, Ponikowski P, Poole-Wilson Pea. ESC Guidelines for the diagnosis and treatment of acute and chronic heart failure 2008. The Task Force for the Diagnosis and Treatment of Acute and Chronic Heart Failure 2008 of the European Society of Cardiology. Developed in collaboration with the Heart Failure Association of the ESC (HFA) and endorsed by the European Society of Intensive Care Medicine (ESICM). Eur J Heart Fail 2008;10(10):933-989.

(2) Coats AJ, Adamopoulos S, Meyer TE, Conway J, Sleight P. Effects of physical training in chronic heart failure. Lancet 1990 Jan 13;335(8681):63-66. 
(3) Pieske B, Edelmann F, Gelbrich G, Düngen H, Fröhling S, Wachter R, Stahrenberg R, Binder $L$ et al. Exercise Training Improves Exercise Capacity and Diastolic Function in Patients With Heart Failure With Preserved Ejection Fraction. Results of the Ex-DHF (Exercise training in Diastolic Heart Failure) Pilot Study.. Am Coll Cardiol 2011;58:17801791.

(4) Kitzman DW, Brubaker PH, Morgan TM, Stewart KP, Little WC. Exercise training in older patients with heart failure and preserved ejection fraction: a randomized, controlled, singleblind trial. Circ Heart Fail 2010 Nov;3(6):659-667.

(5) Rees K, Taylor RS, Singh S, Coats AJ, Ebrahim S. Exercise based rehabilitation for heart failure. Cochrane Database Syst Rev 2004;(3)(3):CD003331.

(6) Chicco AJ. Exercise training in prevention and rehabilitation: which training mode is best? Minerva Cardioangiol 2008 Oct;56(5):557-570.

(7) Papathanasiou G, Tsamis N, Georgiadou P, Adamopoulos S. Beneficial effects of physical training and methodology of exercise prescription in patients with heart failure. Hellenic J.Cardiol. 2008 Jul-Aug;49(4):267-277.

(8) Bjarnason-Wehrens B, McGee H, Zwisler AD, Piepoli MF, Benzer W, Schmid JP, Dendale P, Pogosova NG, Zdrenghea D, Niebauer J, Mendes M, Cardiac Rehabilitation Section European Association of Cardiovascular Prevention and Rehabilitation. Cadiac rehabilitation in Europe: results from the European Cardiac Rehabilitation Inventory Survey. Eur J Cardiovasc Prev Rehabil 2010;17:410-418.

(9) Piepoli MF, Davos C, Francis DP, Coats AJ, ExTraMATCH Collaborative. Exercise training meta-analysis of trials in patients with chronic heart failure (ExTraMATCH). BMJ 2004 Jan 24;328(7433):189.

(10) Flynn KE, Pina IL, Whellan DJ, Lin L, Blumenthal JA, Ellis SJ, et al. Effects of exercise training on health status in patients with chronic heart failure: HF-ACTION randomized controlled trial. JAMA 2009 Apr 8;301(14):1451-1459.

(11) Jaarsma T, Wal MHL van der, Lesman-Leegte I, Luttik MLA, Hogenhuis J, Veeger NJGM, Sanderman R, Hoes AW, Gilst WH van, Lok DJA, Dunselman PHJM, Tijssen JGP, Hillege HL, Veldhuisen DJ van, for the $\mathrm{COACH}$ study group. Effects of moderate and intensive disease management program on outcome in patients with heart failure. The 
Coordinating Study evaluating Outcomes of Advising and Counselling in Heart Failure (COACH). Arch Intern Med 2008;168:316-324.

(12) Keteyian SJ, Ellis SJ, Houston MN, et al. A dose-response analysis of patients with heart failure enrolled in a controlled trial investigating outcomes of exercise training (HFACTION). Amercian College of Cardiology 58th Annual Scientific Session Late Break Clinical Trial Oral Abstract Presentation 2009 March 29.

(13) Keteyian S, Piña I, Hibner B, Fleg J. Clinical Role of Exercise Training in the Management of Patients With Chronic Heart Failure. Journal of Cardiopulmonary Rehabilitation and Prevention 2010;30:67-76.

(14) van der Wal MH, Jaarsma T, Moser DK, Veeger NJ, van Gilst WH, van Veldhuisen DJ. Compliance in heart failure patients: the importance of knowledge and beliefs. Eur Heart $\mathrm{J}$ 2006 Feb;27(4):434-440.

(15) McKelvie RS, Teo KK, Roberts R, et al. Effects of exercise training in patients with heart failure: The Exercise Rehabilitation Trial (EXERT). Am Heart J 2002;144:23-30.

(16) Held C, lqbals R, Lear SA, Rosengren A, Islam S, Mathew J, Yusuf S. Physical activity levels, ownership of goods promoting sedentary behaviour and risk of myocardial infarction: results of the INTERHEART study. European Heart Journal 2012. doi:10.1093/eurheartj/ehr432.

(17) Jolliffe J, Rees K, Taylor RRS, Thompson DR, Oldridge N, Ebrahim S. Exercise-based rehabilitation for coronary heart disease (Review). Cochrane Database Syst Rev 2001.

(18) Wittmer M, Volpatti M, Piazzalonga S, Hoffmann A. Expectation, satisfaction, and predictors of dropout in cardiac rehabilitation. Eur J Cardiovasc PRev Rehab 2011 July 25.

(19) Piepoli M, Conraads V, Corrà U, Dickstein K, Francis D, Jaarsma T, McMurray J et al. Exercise training in heart failure: from theory to practice. A consensus document of the Heart Failure Association and the European Association for Cardiovascular Prevention and Rehabilitation. Eur J Heart Fail 2011;13:347-357.

(20) McDonagh TA, Blue L, Clark AL, Dahlström U, Ekman I, Lainscak M, McDonald K, Ryder M, Strömberg A, Jaarsma $T$, on behalf of Heart Failure Association Committee on Patient Care. European Society of Cardiology Heart Failure Association Standards for delivering heart failure care. Eur J Heart Fail 2011;13:235-241. 
(21) Lainscak M, Blue L, Clark AL, Dahlström U, Dickstein K, Ekman I, McDonagh T, McMurray JJ, Ryder M, Stewart S, Strömberg A, Jaarsma T. Self-care management of heart failure: practical recommendations from the Patient Care Committee of the Heart Failure Association of the European Society of Cardiology. Eur J Heart Fail 2011;13:115-126.

(22) World Health Organization. WHO | Adherence to long-term therapies: evidence for action. WHO 2003:10/11/2010.

(23) International Society of Pharmacoeconomics and Outcome Research-ISPOR, Medication Compliance and Persistence Special Interest Group (MCP). 2012; Available at: http://www.ispor.org/sigs/MCP accomplishments.asp\#definition.

(24) Cramer J.A., Roy A, Burrell A, Fairchild C.J., Fuldeore MJ, Ollendorf D.A, Wong PK. Medication compliance and persistence:terminology and definitions. Value Health 2008;11(1):44-47.

(25) Vanhees L, Lefevre Jm Philippaerts R, Martens M, Huygens W, Troosters T, Beunen G. How to assess physical activity? How to assess physical fitness? Eur J Cardiovasc Prev Rehabil 2005;12:102-111.

(26) Beckie TMTM BJ. Predicting cardiac rehabilitation attendance in a gender-tailored randomized clinical trial. Journal of cardiopulmonary rehabilitation and prevention 2010;30(3):147-156.

(27) Bjarnason-Wehrens B, Grande G, Loewel H, Völler H, Mittag O. Gender-specific issues in cardiac rehabilitation: do women with ischaemic heart disease need specially tailored programmes? Eur J Cardiovac Prev Rehabil 2007 Apr;14(2):163-71.

(28) Rivett MJ, Tsakirides C, Pringle A, Carroll S, Ingle L, Dudfield M. Physical activity readiness in patient withdrawals from cardiac rehabilitation. Br J Nurs 2009 Feb;18(3):18891.

(29) Jones LW, Farrell JM, Jamieson J and Dorsch DD. Factors Influencing Enrollment in a Cardiac Rehabilitation Exercise Program. Can J Cardiovasc Nurs 2003;13(1):11-15.

(30) Parkosewich JA. Cardiac rehabilitation barriers and opportunities among women with cardiovascular disease. Cardiol Rev 2008;16(1):36-52. 
(31) Daly J, Sindone AP, Thompson DR, Hancock K, Chang E, Davidson P. Barriers to participation in and adherence to cardiac rehabilitation programs: a critical literature review. Prog Cardiovasc Nurs 2002 Winter;17(1):8-17.

(32) Caulin-Glaser T, Maciejewski PK, Snow R, LaLonde M, Mazure C. Depressive symptoms and sex affect completion rates and clinical outcomes in cardiac rehabilitation. Prev Cardiol 2007 winter;10(1):15-21.

(33) Jones MI, Greenfield S, Jolly K, BRUM Trial Steering Committee. Patients' experience of home and hospital based cardiac rehabilitation: a focus group study. Eur J Cardiovasc Nurs 2009 Mar;8(1):9-17.

(34) Wingham J, Dalal HM, Sweeney KG, Evans PH. Listening to patients: choice in cardiac rehabilitation. Eur J Cardiovasc Nurs 2006 Dec;5(4):289-94.

(35) Jolly K, Taylor R, Lip GY, Greenfield S, Raftery J, Mant J, et al. The Birmingham Rehabilitation Uptake Maximisation Study (BRUM). Home-based compared with hospitalbased cardiac rehabilitation in a multi-ethnic population: cost-effectiveness and patient adherence. Health Technol Assess 2007 Sep;11(35):1-118.

(36) Jones M, Jolly K, Raftery J, Lip GYH and Greenfield S, on behalf of BRUM Steering Committee. 'DNA' may not mean 'did not participate': a qualitative study of reasons for nonadherence at home- and centre-based cardiac rehabilitation. Family Practice 2007;24:343357.

(37) Marzolini S, Mertens DJ, Oh PI, Plyley MJ. Self-reported compliance to home-based resistance training in cardiac patients. Eur J Cardiovasc Prev Rehabil 2010 Feb;17(1):35-41.

(38) Farley RL, Wade TD, Birchmore L. Factors influencing attendance at cardiac rehabilitation among coronary heart disease patients. Eur J Cardiovasc Nurs 2003 Sep;2(3):205-12.

(39) Marzolini S, Brooks D, Oh PI. Sex differences in completion of a 12-month cardiac rehabilitation programme: An analysis of 5922 women and men. European Journal of Cardiovascular Prevention and Rehabilitation 2008;15(6):698-703.

(40) van der Wal M, Jaarsma T. Adherence in heart failure in the elderly: Problem and possible solutions. Inter 2008;125:203-208. 
(41) Corvera-Tindel T, Doering LV, Gomez T, Dracup K. Predictors of noncompliance to exercise training in heart failure. J Cardiovasc Nurs 2004 jul-Aug;19(4):269-77.

(42) Tierney S, Elwers H, Sange C, Mamas M, Rutter MK, Gibson M, Neyses L, Deaton C. What influences physical activity in people with heart failure? A qualitative study. International Journal of Nursing Studies 2011;48(1234):1243.

(43) Brown TM, Hernandez AF, Bittner V, Cannon CP, Ellrodt G, Liang L, Peterson ED, Piña IL, Safford MM, Fonarow GC, American Heart Association Get With The Guidelines Investigators. Predictors of cardiac rehabilitation referral in coronary artery disease patients: findings from the American Heart Association's Get With The Guidelines Program. J Am Coll Cardiol 2009 Aug 4;54(6):515-521.

(44) British Heart Foundation. The National Audit of Cardiac Rehabilitation: Annual Statistical Report. 2011.

(45) Liu L. Changes in cardiovascular hospitalization and comorbidity of heart failure in the United States: findings from the National Hospital Discharge Surveys 1980-2006. Int J Cardiol 2011 May 19;149(1):29-45.

(46) Leegte I, Jaarsma T, Sanderman R, et al. Depressive symptoms are prominent among elderly hospitalised heart failure patients. Eur J Heart Fail 2006;8:634-640.

(47) Pressler SJ, Subramanian U, Kareken D, et al. Cognitive deficits and healthrelated quality of life in chronic heart failure. J cardiovasc Nurs 2010;25:189-198.

(48) Beckers PJ, Denollet J, Possemiers NM, Wuyts K, Vrints CJ, Conraads VM. Maintaining physical fitness of patients with chronic heart failure: a randomized controlled trial. Eur $\mathrm{J}$ Cardiovac Prev Rehabil 2010;17:660-667.

(49) MeSH. 2010; Available at: http://www.ncbi.nlm.nih.gov/mesh.

(50) Coghill N, Cooper A. Motivators and de-motivators for adherence to a program of sustained walking. Preventive Medicine 2009;49:24-27.

(51) Fernandez RS, Salamonson Y, Griffiths R, Juergens C, Davidson P. Sociodemographic predictors and reasons for participation in an outpatient cardiac rehabilitation programme following percutaneous coronary intervention. Int J Nurs Pract 2008 06;14(3):237-242. 
(52) Perry CK, Bennett JA. Heart disease prevention in women: promoting exercise. J Am Acad Nurse Pract 2006 Dec;18(12):568-73.

(53) Estrella-Holder E. ...that exercise training is safe, useful and effective therapy and does not worsen cardiac function in heart failure? Can J Cardiovasc Nurs 2011;21(2):47-48.

(54) Löfvenmark C, Mattiasson AC, Billing E, Edner M. Perceived loneliness and social support in patients with chronic heart failure. Eur J Cardiovasc Nurs 2009 Oct;8(4):251-258.

(55) Barlow JH, Turner AP, Gilchrist M. A randomised controlled trial of lay-led selfmanagement for myocardial infarction patients who have completed cardiac rehabilitation. Eur J Cardiovasc Nurs 2009 Oct;8(4):293-301.

(56) Fleury J, Kimbrell LC, Kruszewski MA. Life after a cardiac event- Womens experience in healing. Heart \& Lung 1995 Nov-Dec;24(6):474-482.

(57) Tierney S, Mamas M, Woods S, Gibson M, Rutter MK, Neyses L, Deaton C. What strategies are effective for exercise adherence in heart failure? A systematic review of controlled studies. Heart Failure Review 2012;17(1):107-115.

(58) Dolansky MA, Stepanczuk B, Charvat JM, Moore SM. Women's and men's exercise adherence after a cardiac event. Research in Gerontological Nursing 2010;3:30-38.

(59) Duncan KD PB. Effects of an exercise adherence intervention on outcomes in patients with heart failure. Rehabil Nurs 2003;28(117):122.

(60) Gary R. Exercise self-efficacy in older women with diastolic heart failure: Results of a walking program and education intervention. Journal of Gerontological Nursing 2006;32:3139.

(61) Pozehl B, Duncan K, Hertzog M, Norman JF. Heart failure exercise and training camp: Effects of a multicomponent exercise training intervention in patients with heart failure. Heart Lung 2010;39:S1-S13.

(62) Oka RK, Gortner SR, Stotts NA, Haskell WL. Predictors of physical activity in patients with chronic heart failure secondary to either ischemic or idiopathic dilated cardiomyopathy. American Journal of Cardiology 1996;77(159):163. 
(63) van der Bij, A.K., Laurant, M.G.H., \& Wensing, M. Effectiveness of physical activity interventions for older adults: A review. American Journal of PreventiveMedicine 2002;22:120-133.

(64) Anderson ES, Wojcik JR, Winett RA, Williams DM. Social-cognitive determinants of physical activity: The influence of social support, self-efficacy, outcome expectations and self-regulation among participants in a church-based health promotion study. Health Psychology 2006;25:510-520. 
Table 1. Prescription of/ assessment of adherence to exercise training in heart failure patients.

\begin{tabular}{|c|c|c|c|c|c|c|c|c|c|c|c|c|c|c|c|c|c|c|c|c|c|}
\hline \multirow{2}{*}{$\begin{array}{l}\text { Modality of } \\
\text { exercise } \\
\text { training } \\
\text { program }\end{array}$} & \multicolumn{7}{|c|}{ Endurance } & \multicolumn{7}{|c|}{ Respiratory } & \multicolumn{7}{|c|}{ Resistance/Strength } \\
\hline & $\begin{array}{l}\text { Mo } \\
\mathrm{n}\end{array}$ & Tue & $\begin{array}{l}\text { We } \\
\text { d }\end{array}$ & $\begin{array}{l}\text { Th } \\
\text { u }\end{array}$ & $\mathbf{F r}$ & $\begin{array}{l}\text { Sa } \\
t\end{array}$ & $\begin{array}{l}\mathrm{S} \\
\mathrm{u}\end{array}$ & $\begin{array}{l}\text { Mo } \\
\mathrm{n}\end{array}$ & Tue & $\begin{array}{l}\text { We } \\
\text { d }\end{array}$ & $\begin{array}{l}\text { Th } \\
u\end{array}$ & $r$ & $\begin{array}{l}\text { Sa } \\
\text { t }\end{array}$ & Su & $\begin{array}{l}\text { Mo } \\
n\end{array}$ & Tue & $\begin{array}{l}\text { We } \\
\text { d }\end{array}$ & Thu & $\mathbf{F r}$ & $\begin{array}{l}\text { Sa } \\
\text { t }\end{array}$ & $\begin{array}{l}\text { S } \\
\text { u }\end{array}$ \\
\hline $\begin{array}{l}\text { Frequency } \\
\text { of sessions } \\
\text { (times/day) }\end{array}$ & & & & & & & & & & & & & & & & & & & & & \\
\hline $\begin{array}{l}\text { Duration of } \\
\text { session } \\
(\mathrm{min} / \mathrm{sessior} \\
)\end{array}$ & & & & & & & & & & & & & & & & & & & & & \\
\hline $\begin{array}{l}\text { Intensity } \\
\text { Endurance } \\
\text { training [\% } 0 \\
\text { peak capacit) } \\
\left(\mathrm{VO}_{2} \text { peak) o }\right. \\
\text { training heart } \\
\text { rate] } \\
\text { Resistance } \\
\text { training [\% 0 } \\
\text { one repetitior } \\
\text { maximum (\% } \\
\text { 1-RM)] } \\
\text { Respiratory } \\
\text { training [\% } \\
\text { maximal } \\
\text { inspiratory } \\
\text { mouth } \\
\text { pressure } \\
\text { (\%PI }{ }_{\text {max })]}\end{array}$ & & & & & & & & & & & & & & & & & & & & & \\
\hline $\begin{array}{l}\text { Repetitions } \\
\text { (number/day } \\
\text { ) }\end{array}$ & & & & & & & & & & & & & & & & & & & & & \\
\hline Borg & & & & & & & & & & & & & & & & & & & & & \\
\hline
\end{tabular}




\begin{tabular}{|l|l|l|l|l|l|l|l|l|l|l|l|l|l|l|l|l|l|l|l|}
\hline [subjective \\
rating of \\
perceived \\
exertion] \\
scale
\end{tabular}


Table 2. Objective methods of exercise training assessment.

\begin{tabular}{|l|l|l|}
\hline Assessment method & Advantages & Limitations \\
\hline $\begin{array}{l}\text { Pedometers: i.e. walking } \\
\text { training assessment }\end{array}$ & $\begin{array}{l}\text { Inexpensive, easy to wear, } \\
\text { unobtrusive. }\end{array}$ & $\begin{array}{l}\text { Not appropriate for monitoring complex } \\
\text { movements, cycling or movements on } \\
\text { graded terrain. } \\
\text { No recording of horizontal or upper- } \\
\text { body movements. }\end{array}$ \\
\hline $\begin{array}{l}\text { Accelerometers: ie } \\
\text { monitoring the intensity of } \\
\text { the movement. }\end{array}$ & $\begin{array}{l}\text { Possibility of measuring a specific } \\
\text { activity. Inexpensive, easy to } \\
\text { wear, unobtrusive. }\end{array}$ & $\begin{array}{l}\text { No recording of horizontal or upper- } \\
\text { body movements. }\end{array}$ \\
\hline $\begin{array}{l}\text { Pulsometers: ie } \\
\text { Monitoring training heart } \\
\text { rate. }\end{array}$ & $\begin{array}{l}\text { Inexpensive, easy to wear, } \\
\text { unobtrusive. }\end{array}$ & $\begin{array}{l}\text { Not reliable for sedentary or very light- } \\
\text { intensity training. }\end{array}$ \\
\hline $\begin{array}{l}\text { ECG telemonitoring: ie. } \\
\text { monitoring training heart } \\
\text { rate, arrhythmias, } \\
\text { conduction disturbances, } \\
\text { ST-T segment (silent } \\
\text { ischaemia). }\end{array}$ & $\begin{array}{l}\text { Useful for monitoring exercise } \\
\text { training below ischaemic } \\
\text { threshold, detection of } \\
\text { arrhythmias and precise recording } \\
\text { of training heart rate. }\end{array}$ & $\begin{array}{l}\text { Expensive. Need special device, } \\
\text { monitoring staff, monitoring centre. } \\
\text { Not reliable for sedentary or very light- } \\
\text { intensity training. }\end{array}$ \\
\hline
\end{tabular}


Table 3. Barriers for exercise in HF reported in literature.

\begin{tabular}{|l|l|}
\hline & Barriers \\
\hline Patient-related & Older age \\
Low level of education \\
Low socioeconomic status \\
Minority status \\
Anxiety and depression \\
Logistical problems \\
Lack of motivation \\
Lack of insight in benefits \\
Lack of time
\end{tabular}


Table 4. Recommendations for clinicians to help patients to overcome barriers to exercise.

\section{Patient related:}

Optimise HF management and manage co-morbid conditions

Ask patients about exercise and activity levels at every visit

Assess preferred mode of exercise

Ask patients about their attitudes and beliefs regarding exercise with HF

Use a patient-centred approach that engages and respects the patient as a therapeutic partner

\section{Address barriers to exercise:}

- Screen for depression and treat according to guidelines

- Improve pain relief and joint mobility for arthritis

- Ask HF patients who are exercising to encourage others either in face-to-face encounters or via recorded videocasts

- Discuss competing priorities and how exercise can fit into their lives

- Support patients in problem-solving, and setting realistic goals for increasing physical activity

\section{Therapy related:}

- Teach patients: Breathing exercises to reduce dyspnea; to rate subjectively perceived exertion as a guide for exercise intensity (recommend activity at $11-13$ on the Borg scale); warning signs for stopping activity (e.g. chest pain, severe dyspnea, dizziness, etc.)

- Support patients: to identify intentions to exercise during hospitalization, to translate intentions into specific plans (how, where, and when to perform an action) and detailed planning of how to implement the desired behaviour

- Counselling sessions based on motivational interviewing strategies may benefit patients who have not considered exercise or are resistant to exercise. These can be brief, (e.g. $15 \mathrm{~min}$ ) and there is greater benefit with more than one session

- Encourage activities that the patient prefers: e.g. gardening, dancing, water gymnastics etc.

- Involve family and friends if possible and enlist their support in encouraging activity

\section{Give information on:}

- Safety of exercise

- How exercise relates to improvements in symptoms and activity tolerance

- The importance of exercise as a component of HF therapy

\section{Related to professional and organisation:}

- Refer to exercise training or cardiac rehabilitation if possible

- Support training in cognitive behavioural strategies and motivational interviewing for clinicians

- Know what resources are available in the community

- Determine availability of several modes/possibilities of programs (group, individual, home based, hospital based) to make tailoring of interventions possible

- Have referral system in place

- Include referral and completion of CR in performance criteria 


\section{Remember:}

- Monitoring of activities (exercise logs or diaries, pedometers or accelerometers. Newer accelerometers provide graphic feedback and recognition of goals accomplished)

- Congratulating patients on changes made and goals met may increase adherence 